\title{
Surface morphology and structure of reactive materials used in the removal of pollutants generated during the process of coal conversion in the rock mass
}

\author{
Aleksandra Tokarz $^{1}[$ ] Jacek Grabowski \\ Received: 22 October 2018 / Accepted: 8 July 2019 / Published online: 17 July 2019 \\ (c) The Author(s) 2019
}

\begin{abstract}
The technology of permeable reactive barriers in recent years is one of the most frequently developed methods of protecting the soil and water environment against pollution. This technique is the remediation of groundwater where contaminants are removed from an aquifer by the flow through a reactive barrier filled with a reactive material. The novelty of the presented concept is the application of a barrier, limiting the potential risk of liquid and gas pollution in the case of uncontrolled and unpredictable operation, in the emergency situations related to gas leaks to the environment, underground fires and water pollution with substances of high toxicity, during the underground hard coal conversion. The use of the permeable reactive barrier also aimed at limiting the leaching of pollutants away from the georeactor zone, after mining of the deposit. The carried-out tests aimed at determining the possibility of using reactive materials to remove gaseous pollutants from the georeactor surroundings. The research involved the assessment of changes in the structure and morphology of the surface during thermal conversion of active carbon and zeolite samples. The presented results of the study show that the appropriate selection of reactive materials in the process of underground coal gasification will allow the reduction of the risk of the spread of gaseous and liquid pollutants in the rock mass.
\end{abstract}

Keywords Permeable reactive barriers $\cdot$ Removal of pollutants $\cdot$ Reactive materials $\cdot$ Georeactor $\cdot$ Coal conversion

\section{Introduction}

The technology of Permeable Reactive Barriers (PRB) may be an effective method in neutralizing pollutants, generated during the underground coal conversion. The Underground Coal Gasification (UCG) is a process based on the extraction and conversion of coal in in situ conditions, forming a synthesis gas, which can be processed to provide raw material to produce electricity, liquid fuels for diesel and jet engines, hydrogen, fertilizer and chemical products. The UCG process may cause deterioration of the environment, both during

Aleksandra Tokarz

atokarz@gig.eu

Jacek Grabowski

jgrabowski@gig.eu

1 Department of Energy Saving and Air Protection, Central Mining Institute, Katowice, Poland

2 Department of Environmental Monitoring, Central Mining Institute, Katowice, Poland the process (as a result of a failure) and many years after its completion (leaching residues from the post-process cavern by a natural inflow of water. Process of Underground Coal Gasification involves risks of uncontrolled/unpredictable course of the gasification process. Such events may occur especially during gasification of coal seams deposited in a complex geological structure, gasification of residues of coal, and processes carried out in areas characterized by high risk of rock burst or seismic activity. A sudden rise in temperature or pressure, when the quality of sealing of the georeactor becomes weaker, may lead to dangerous initiation of changes, mechanical phenomena, and a risk that contaminated liquids and reactive gases leak outside the georeactor.

The use of reactive materials may help to reduce and/ or eliminate the content of phenols, BTEX, mono- and polycyclic aromatic hydrocarbons, cyanides, ammonium, chloride, sulphate and heavy metals in aquifers and gaseous pollutants, i.e. hydrogen, methane, ammonia, hydrogen sulphide, carbon monoxide and carbon dioxide (Dudzinska and Cygankiewicz 2015; Dudzińska 2016; Kapusta et al. 2013; Obiri-Nyarko et al. 2014). The PRB method involves 
the use of reactive material located on the flow path of the pollutants streak, to neutralize pollutants or transform them into forms that are less dangerous to the environment. The main advantages of the barriers are the possibility of using the available and effective reactive materials, low energy costs and relatively low maintenance and monitoring costs, with the exception of the initial installation costs. In addition, this method allows for the use of a mixture of materials, selectively neutralizing a wide range of pollutants. Another advantage is the location of an in situ barrier enabling onsite operation without the need to discharge pollutants to the surface; it does not have any impact on the direction and flow of waters (Fronczyk 2006). The use of underground barriers requires occasional monitoring after the end of the process in the georeactor, to ensure proper functioning of the barrier. As any technology, it also has limitations in cleaning pollutants flowing through the barrier space. In addition, this method requires proper terrain and aquifer characteristics, and exact location of pollutants before the barrier installation. Currently, there is a limited number of field data regarding the long-term use of the underground barriers. The studies described so far in the literature concerned the barriers located in shallow installations, whereas in the case of the UCG process, the location of the barrier requires deep locations (Naval Facilities Engineering Command 2012). The use of the barrier at greater depths is associated with higher costs and more difficult technical conditions related to the location of the installation. It is expected that in the next few years, the methods of constructing deep installations will develop significantly, first of all in terms of the possibility of installing more effective barriers using the fast-reacting media (Połoński et al. 2017). The studies are particularly important because the reactive materials may need to be removed or replaced at the end of work, and may also need monitoring, particularly in the areas where longlasting pollutions occur, or in the areas where water flow is slow. The assessment of pollution allows to indicate whether the pollutants may undergo bio-degradation or removal by mechanisms such as sorption, precipitation and redox reactions in the barrier, and whether they show too high or low concentrations in water. This type of assessment is carried out to determine whether the hydrogeological conditions, including groundwater velocity, depth and hydraulic conductivity in place, are appropriate to the use of PRB (Yin et al. 2017; Naval Facilities Engineering Command 2012; Obiri-Nyarko et al. 2014).

In the last decade, huge progress was made in the identification of the new reactive materials for disposal of the liquid and gaseous pollutants. Mostly, the activated carbon, active coke, carbon and zeolite molecular sieves, corundum, aluminium and silica gel are used for sorption of gases. In the present work, reactive materials were selected based on the experience of previous research carried out at the

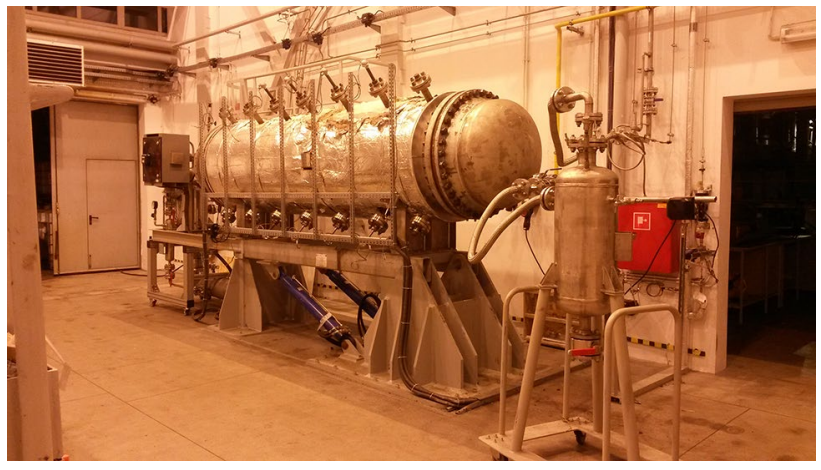

Fig. 1 Location of process gas drawn for the gasification system

Central Mining Institute (Ludwik-Pardała 2013; Dudzinska and Cygankiewicz 2015). The materials used were subjected to sorption of gases generated during a real coal gasification experiment. The study described in the article will allow the estimation of the possibility of limitation of spread of the gaseous pollutants to the aqueous environment during the coal gasification process, using the reactive material under in situ conditions. It is planned to use sorption materials to eliminate or reduce the potential limitations of individual materials, i.e. improving permeability, providing many mechanisms for removing the pollutants and accelerating the disposal of the pollutants (Fadaei et al. 2017; Liu et al. 2007; Wołowiec et al. 2017; Zhang et al. 2013). The new approach is to use the same reactive materials to remove water and/or gas pollutants. Additionally, in the case of the UCG process, operations are carried out under variable conditions that directly affect the properties of the reactive material used. In the case of the underground coal gasification, the use of sorbents may be effective in a form of a filling of the postprocess cavern, after completion of the gasification process.

\section{Materials and methods}

The choice of the appropriate sorbent was made on the basis of the following parameters: sorption capacity assessment, reactivity, stability, regeneration capacity, lack of harmful effects of by-products on the environment, as well as the availability and price. The activated carbon with a grain size of 4-8 $\mathrm{mm}$ and the zeolite (Slovak clinoptilolite) with a grain size of 1-2.5 mm were used for the study.

During the ex situ coal gasification experiment, carried out at the Central Mining Institute, the samples of activated carbon and zeolite were subjected to sorption of the process gas (Fig. 1). The gasification experiment was carried out for the lignite derived from the Oltenia deposit, at the temperature of $600{ }^{\circ} \mathrm{C}$ and pressure of 10 bars, during $72 \mathrm{~h}$, under oxygen and $\mathrm{CO}_{2}$ conditions (Wiatowski et al. 2019). At the 44th hour of the coal gasification process, the resulting 
Table 1 The average composition of the process gas and the gas composition at the moment of drawing for the gasification system

\begin{tabular}{lcc}
\hline Gas & $\begin{array}{l}\text { Average gas com- } \\
\text { position 0-72 h } \\
\text { [vol.\%] }\end{array}$ & $\begin{array}{l}\text { Gas composition at the time of drawing } \\
\text { (CG drawing-detection) (44th hour) } \\
\text { [vol.\%] }\end{array}$ \\
\hline $\mathrm{H}_{2}$ & 7.96 & $9.201-13.006$ \\
$\mathrm{~N}_{2}$ & 1.00 & $0.880-1.117$ \\
$\mathrm{CH}_{4}$ & 1.99 & $2.578-3.423$ \\
$\mathrm{CO}$ & 3.19 & $2.364-4.212$ \\
$\mathrm{CO}_{2}$ & 84.98 & $75.549-80.941$ \\
$\mathrm{C}_{2} \mathrm{H}_{6}$ & 0.10 & $0.189-0.203$ \\
$\mathrm{H}_{2} \mathrm{~S}$ & 0.78 & $1.148-1.204$ \\
\hline
\end{tabular}

process gas was subjected to sorption on the reactive material filling the column with a flow rate of $450 \mathrm{~cm}^{3} / \mathrm{min}$. The composition of the process gas generated during the UCG process is shown in Table 1.

The reactive materials were subjected to Thermogravimetric Analysis (TGA) in the SPT Q6000 ITA Instruments analyzer. A sample of activated carbon and zeolite before and after the gas sorption was placed in the crucible of the measuring device. An inert gas (nitrogen) was fed into the furnace chamber at a set flow rate of $100 \mathrm{ml} / \mathrm{min}$. The conditions for conducting the experiment were established, i.e. the initial temperature $\left(20^{\circ} \mathrm{C}\right)$ and the final temperature $\left(900{ }^{\circ} \mathrm{C}\right)$, at the maximum temperature increase of $50{ }^{\circ} \mathrm{C} /$ $\min$.

To determine the specific surface area, total pore volume and pore size distribution of a sample of activated carbon and zeolite before the gas sorption and after gas desorption, the Autosorb iQ (Quantachrome Instruments) analyzer was used. The samples were degassed under reduced pressure and high temperature.

The evaluation of the surface morphology and microstructure of the selected reactive materials was carried out using the Scanning Electron Microscope (SEM, HITACHI Model SU-3500 N). The essence of SEM scanning microscopy is scanning the sample surface with a nanometre electron beam, formed by the electron-optical system of the microscope. The signal from the surface of the sample is tested using a detector. The magnification of the scanning microscope results from the relation between the size of the areas scanned on the sample and the monitor. The X-ray microanalysis method is based on excitation of the characteristic X-ray by the strongly focused electron beam. The analysis of this radiation allows to determine the chemical composition of the material in a given micro-area. The studies confirmed that as the temperature rises some changes in the structure occur, which manifest itself in a more coarse and porous surface.

Energy-dispersive spectroscopy systems are typically integrated into an SEM instrument. Analysis of the chemical composition of a sample with the EDS detector allows to detect elements with a content of appr. $0.1 \%$ by weight, and to obtain quantitative results using an appropriate calibration. In the quantitative analysis, the background radiation is subtracted from the spectrum, while the qualitative microanalysis involves obtaining a readable spectrum of X-rays from the selected sample fragment. In the quantitative analysis, the concentration of elements is calculated on the basis of the proportional dependence of the characteristic intensity of X-ray radiation on the content of elements in the analysed volume.

\section{Results and discussion}

The study on the reactive materials, which can be used in the permeable reactive barriers, will allow the determination of changes in the sorption capacity of these materials, and to estimate the efficiency of removing of the pollutants, generated during and after completion of the coal conversion process in the rock mass. For the study, there were selected the activated carbon and zeolite.

Samples of activated carbon and zeolite were taken from the sorption column and subjected to thermogravimetric and chromatographic analyses to quantitatively and qualitatively determine the gas products adsorbed in the material. The thermogravimetric curves for the sample of activated carbon and zeolite before the gas sorption and after gas sorption are shown in Figs. 2, 3, 4 and 5.

The results obtained from the TGA showed that up to $150{ }^{\circ} \mathrm{C}$, the weight loss of samples was connected with thermodesorption of water and then, up to the temperature of $900{ }^{\circ} \mathrm{C}$, degassing of the sample occurred.

The presence and amount of gases desorbed from the tested samples testified about the sorption processes of the gaseous products, included in the process gas generated during gasification.

The specific surface area of the activated carbons can range from a few hundred to $2000 \mathrm{~m}^{2} / \mathrm{g}$; however, in practice, there are used carbons with a specific surface area smaller than $1200 \mathrm{~m}^{2} / \mathrm{g}$. In the case of zeolite, the value given in the literature for clinoptilolite falls in the range of $27.7-46.3 \mathrm{~m}^{2} / \mathrm{g}$ (Fronczyk 2006).

Analysing the data in Table 2, it can be concluded that the activated carbon is characterized by good sorption capacity, resulting from the strongly developed specific surface area of SBET $=671.2 \mathrm{~m}^{2} / \mathrm{g}$. Comparing the results of the zeolitespecific surface area before the process to the zeolite after desorption of the gas, no changes were observed, whereas the activated carbon showed a decrease in surface area due to gas sorption. Only the particles of a smaller effective kinetic diameter than the pore holes of the spatial structure of the described materials may undergo sorption in the 
Fig. 2 The thermogravimetric curves for the sample of activated carbon before gas sorption

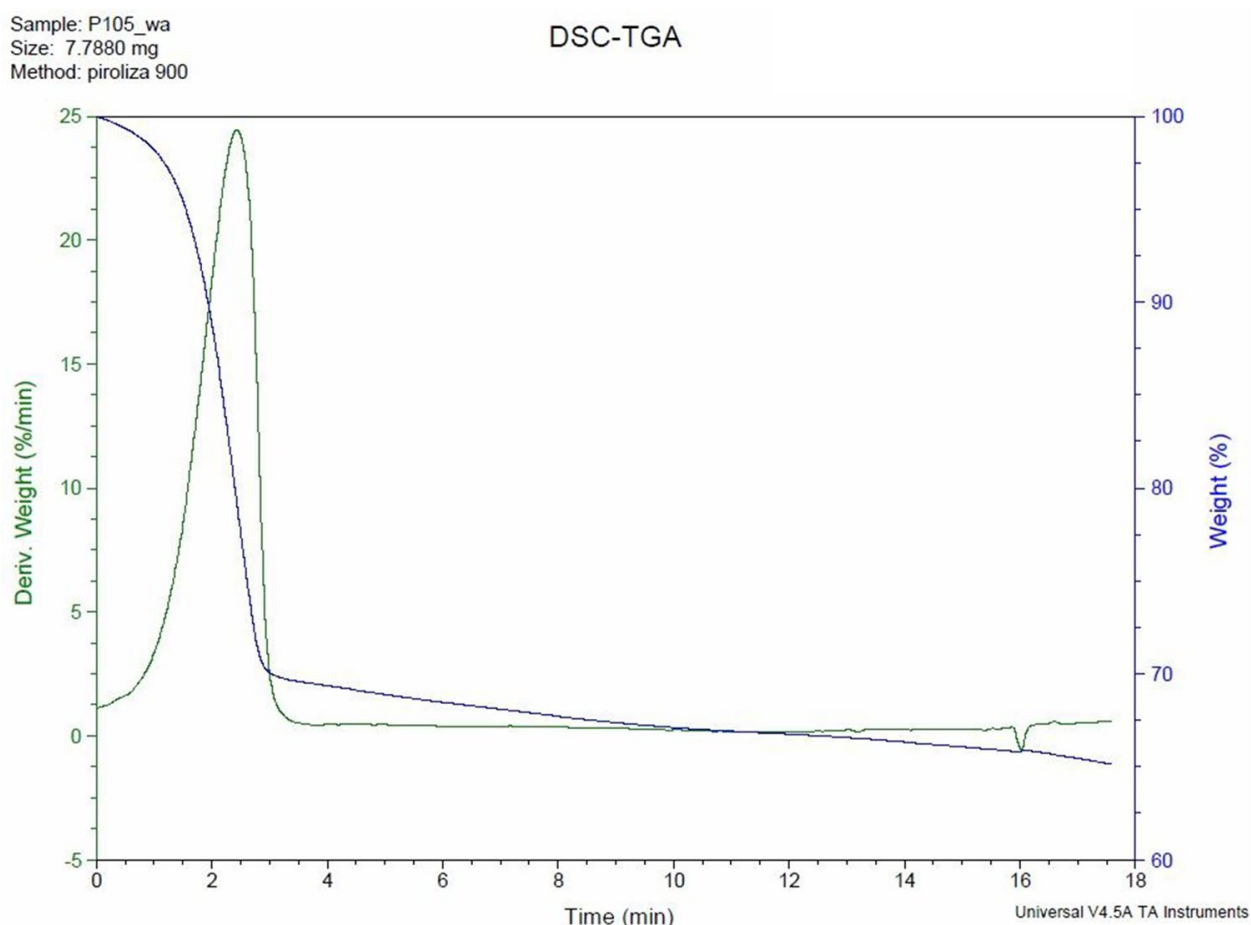

Fig. 3 The thermogravimetric curves for the sample of activated carbon after gas sorption
Sample: P104_wa Method: piroliza

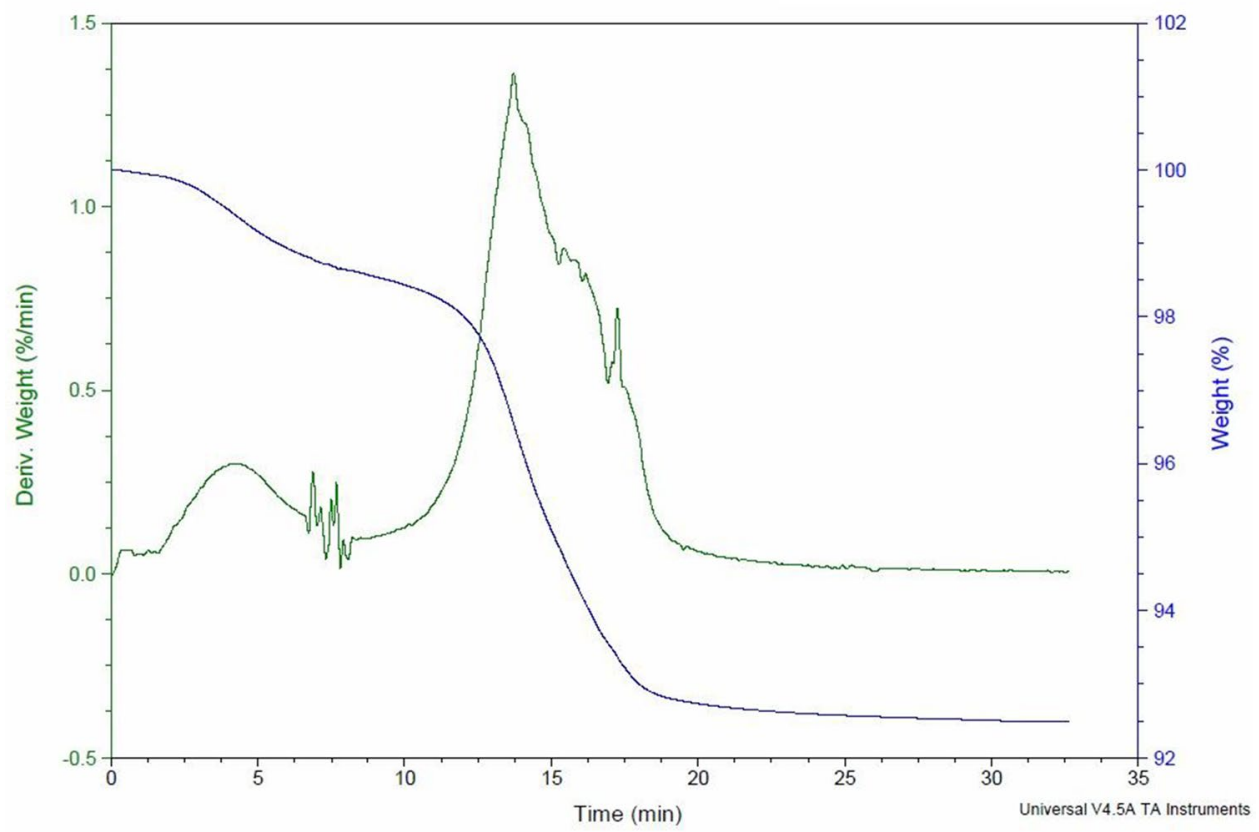

pores. The activated carbon is characterized by the pore size of 1-25 nm, whereas in the case of clinoptilolite, there are mesopores with a predominant diameter of appr. $3.8 \mathrm{~nm}$. In the case of sorption of gases on the reactive materials, carbon dioxide is a well-adsorbed gas due to low activation energy, low chemical reactivity and small particle size with a kinetic diameter of $0.33 \mathrm{~nm}$. The carbon monoxide (kinetic diameter of $0.38 \mathrm{~nm}$ ) and hydrogen (kinetic diameter of $0.29 \mathrm{~nm}$ ) are sorbed in the smallest amount, only on the outer surface of the grain (Dudzińska 2016).

Surface morphology studies of reactive materials and analysis in micro-areas were made using scanning electron microscope with EDS detector. SEM images of samples before the gas sorption, after gas sorption and after 
Fig. 4 The thermogravimetric curves for the sample of zeolite before gas sorption

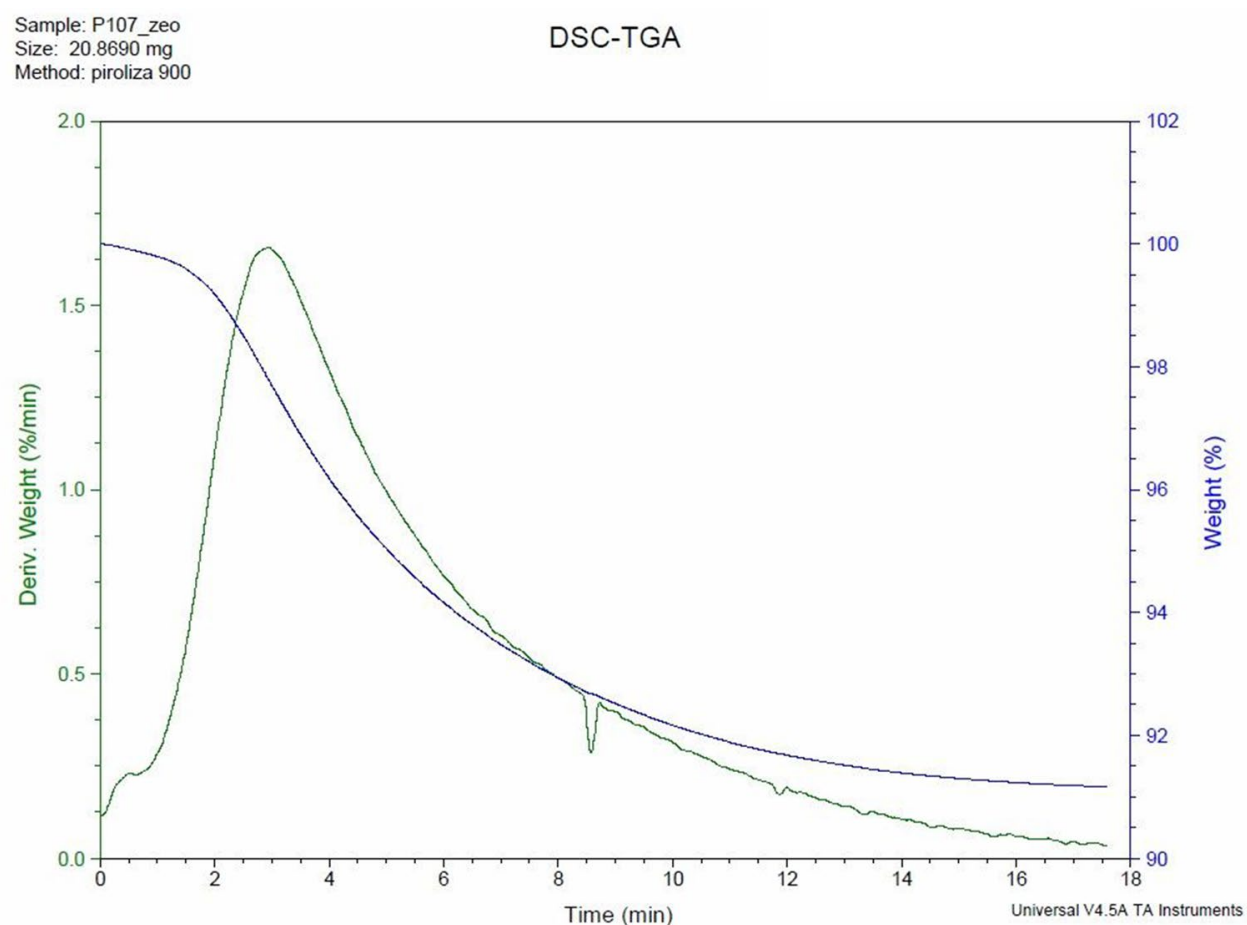

Fig. 5 The thermogravimetric curves for the sample of zeolite after gas sorption

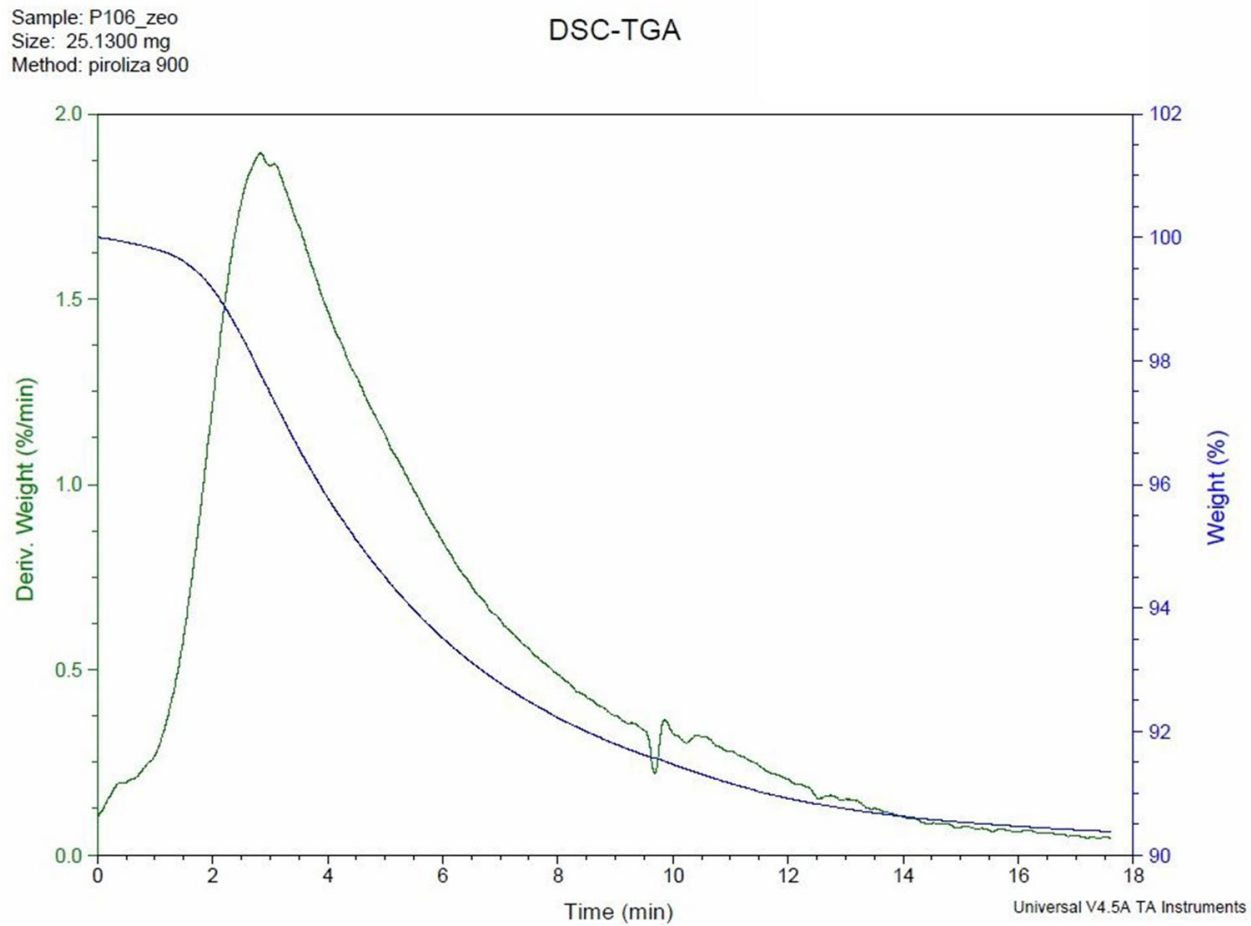

gas desorption were made at $27 \times$ and $1000 \times$ magnification (Figs. 6, 7, 8, 9, 10, 11). The analysis of the chemical composition of the activated carbon sample before sorption, after sorption and after desorption of gas was carried out each time in four micro-areas. The analysis of the chemical composition of the zeolite sample was carried out in six micro-areas (measuring points are marked in Figs. 6, 7, 8, 9, 10, 11).

Examples of EDS spectra for activated carbon and zeolite from selected micro-grain areas are shown in Figs. 12, 13, $14,15,16$ and 17. 
Table 2 Results of the $\mathrm{N}_{2}$ adsorption analysis at $77 \mathrm{~K}$

\begin{tabular}{llccc}
\hline Sample & $\begin{array}{l}\text { Multi-point BET-specific } \\
\text { surface area }\left(\mathrm{m}^{2} / \mathrm{g}\right)\end{array}$ & $\begin{array}{l}\text { DFT pore diameter } \\
(\text { mode })[\mathrm{nm}]\end{array}$ & $\begin{array}{l}\text { Average pore diam- } \\
\text { eter }(\mathrm{nm})\end{array}$ & $\begin{array}{l}\text { Total pore } \\
\text { volume } \\
\left(\mathrm{cm}^{3} / \mathrm{g}\right)\end{array}$ \\
\hline Activated carbon before gas sorption & 671.2 & 0.57 & 2.03 & 0.3406 \\
Activated carbon after gas desorption & 516.2 & 0.55 & 1.97 & 0.2538 \\
Zeolite before gas sorption & 27.6 & 20.62 & 22.74 & 0.1566 \\
Zeolite after gas desorption & 27.8 & 20.62 & 22.61 & 0.1568 \\
\hline
\end{tabular}
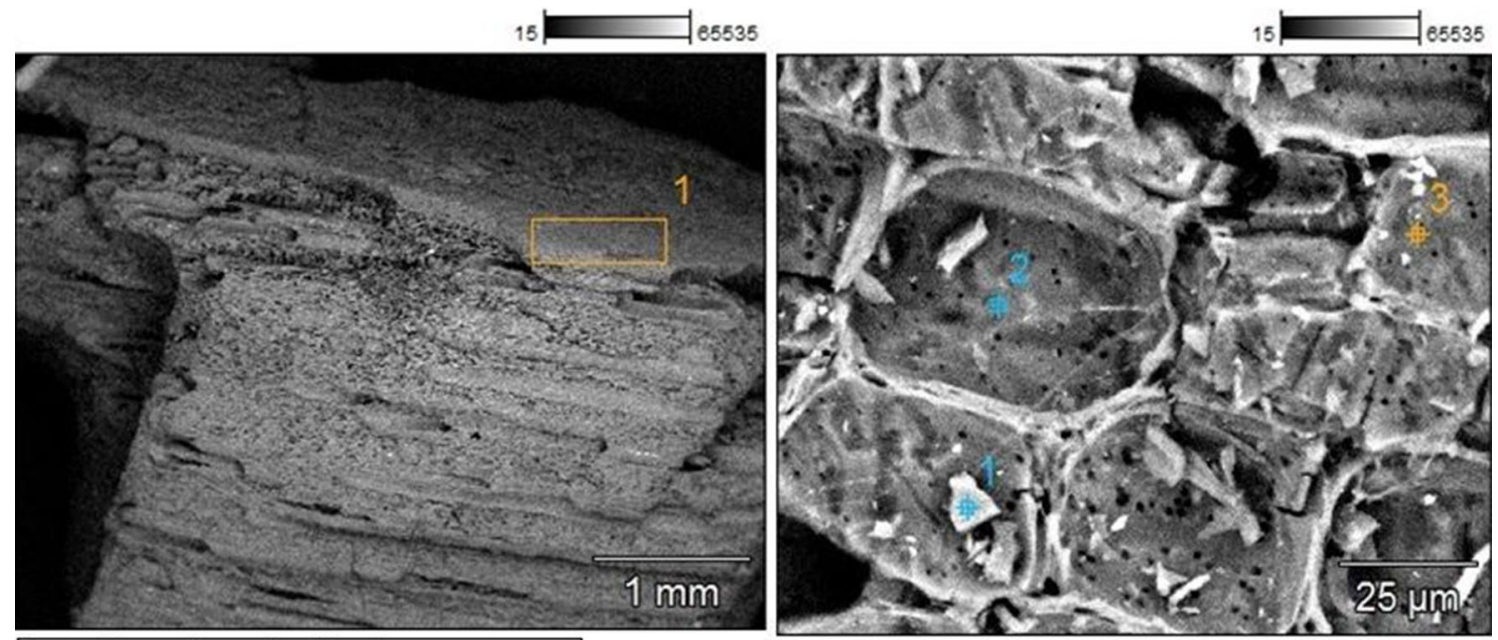

\begin{tabular}{l} 
Image Name: Pure activated carbon \\
Image Resolution: 1024 by 768 \\
Image Pixel Size: $4.70 \mu \mathrm{m}$ \\
Acc. Voltage: $15.0 \mathrm{kV}$ \\
Magnification: 27 \\
\hline
\end{tabular}

Image Name: Pure activated carbon
Image Resolution: 1024 by 768
Image Pixel Size: $0.13 \mu \mathrm{m}$
Acc. Voltage: $15.0 \mathrm{kV}$
Magnification: 1000

Fig. 6 SEM image of the activated carbon sample before gas sorption in a micro-area of 27 and $1000 \times$ magnification
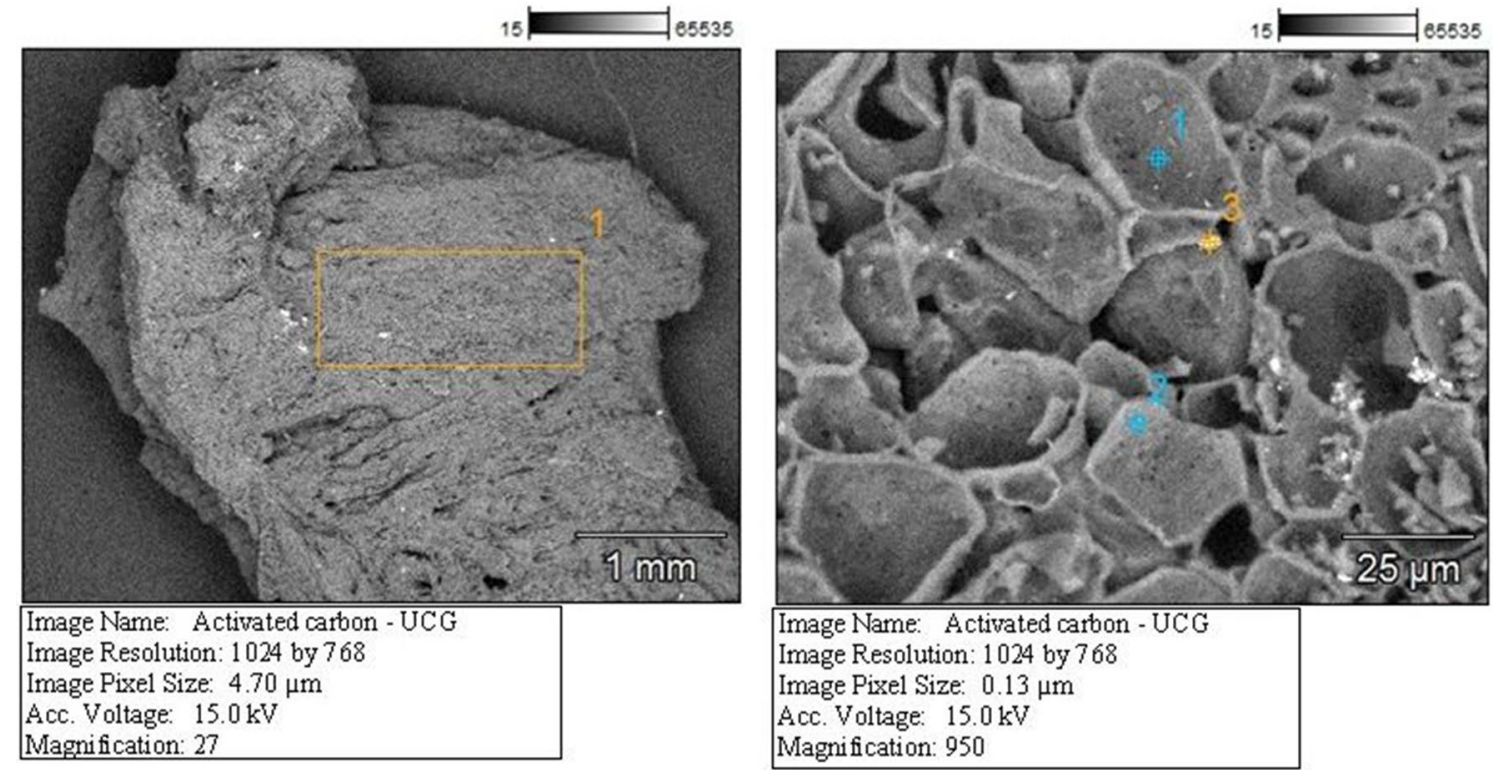

Fig. 7 SEM image of the activated carbon sample after gas sorption in a micro-area of 27 and $950 \times$ magnification 


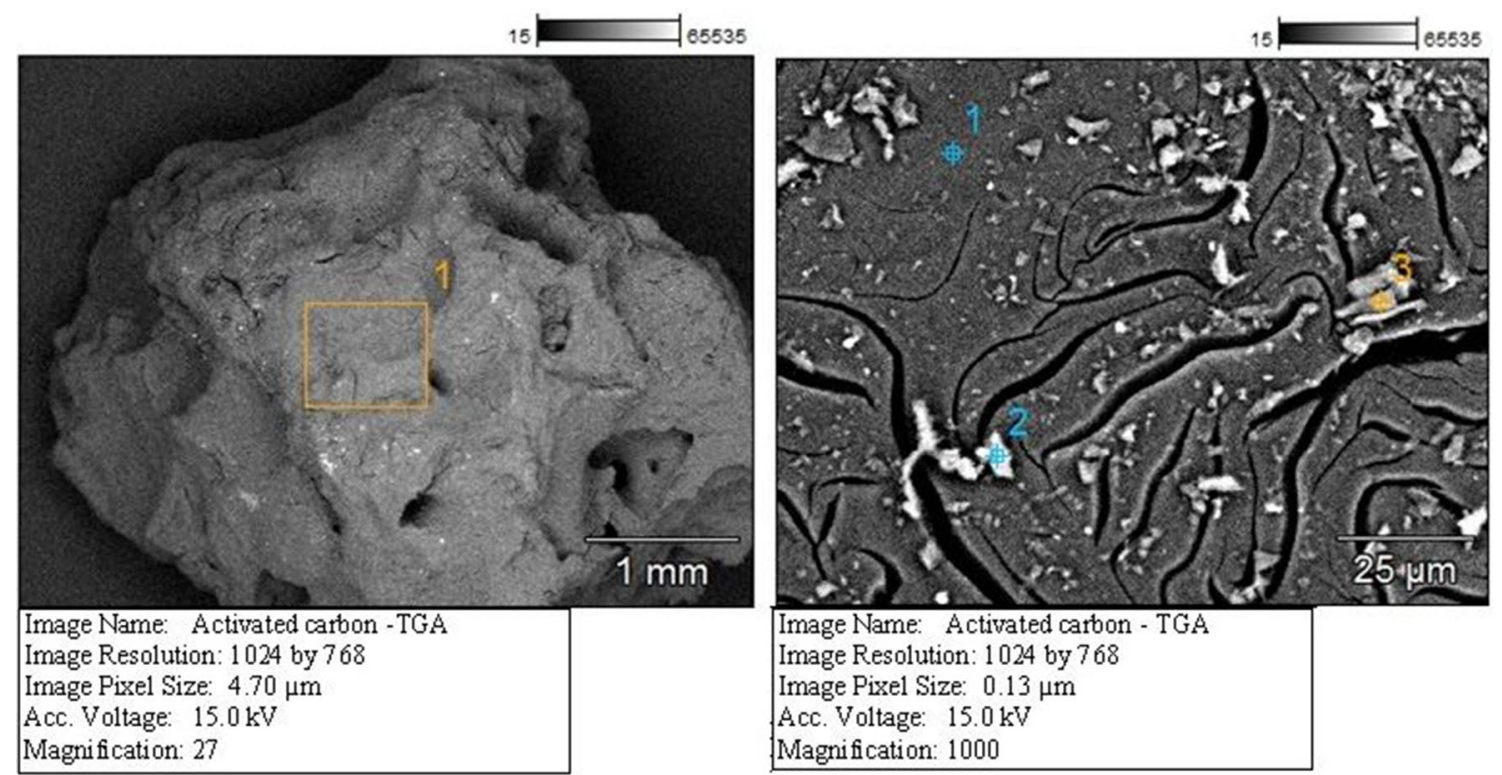

Fig. 8 SEM image of the activated carbon sample after gas desorption in a micro-area of 27 and $1000 \times$ magnification
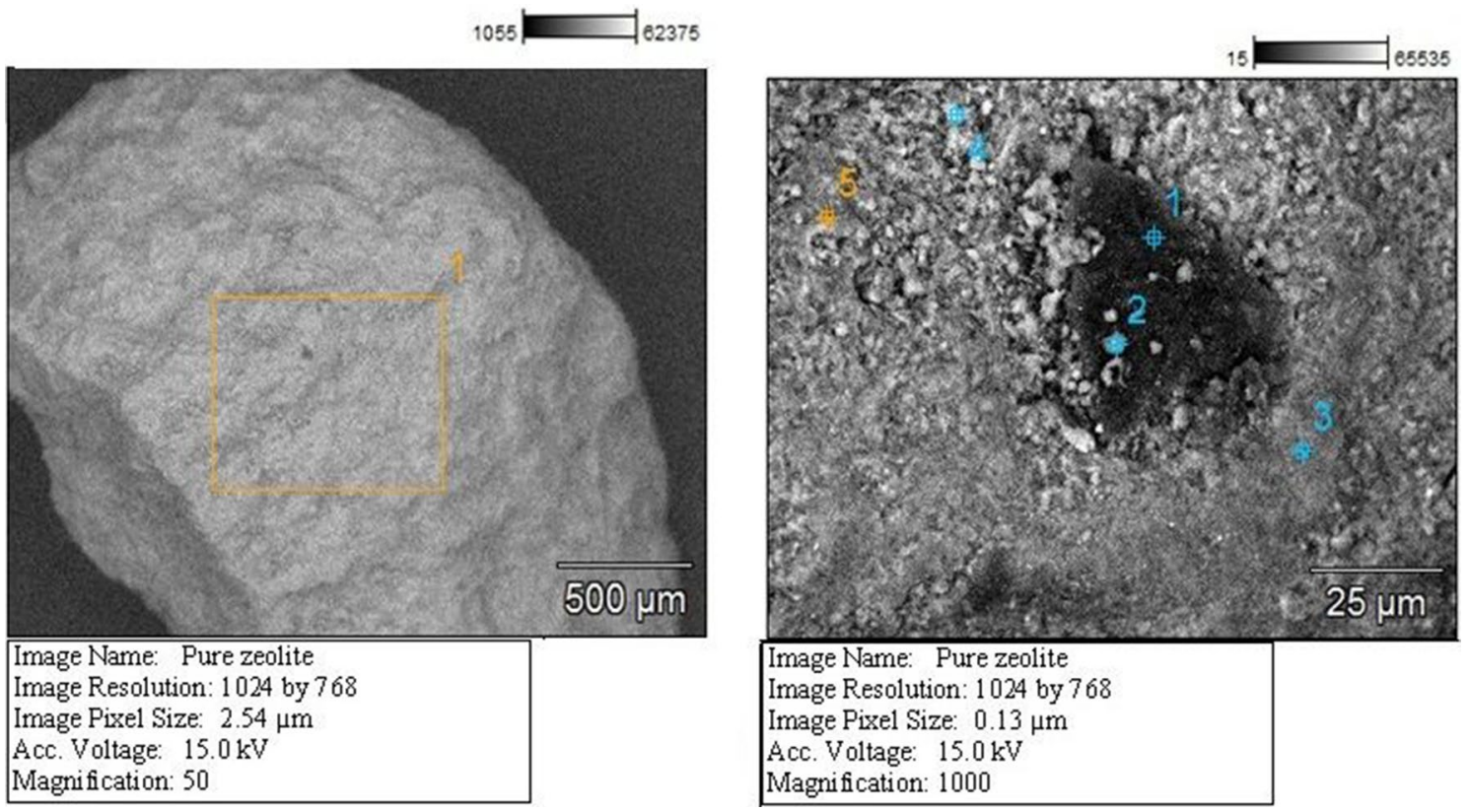

Fig. 9 SEM image of the zeolite sample before gas sorption in a micro-area of 50 and $1000 \times$ magnification

Table 3 shows the average chemical composition of the grains of reactive material samples before sorption, after sorption and after gas desorption.

The activated carbon is a substance consisting mainly of elemental carbon in amorphous form (soot), partly in the form of fine crystalline graphite. In addition to carbon, it usually contains ash, mainly alkali metal oxides and silica. The SEM/EDS tests carried out confirmed that the activated carbon grains consist mainly of carbon and also aluminium, silicon, potassium and magnesium compounds. In the sample of active carbon after gas sorption and desorption, no compounds containing aluminium were determined. No potassium-containing compounds were determined for the sample after gas desorption. Compounds containing calcium 


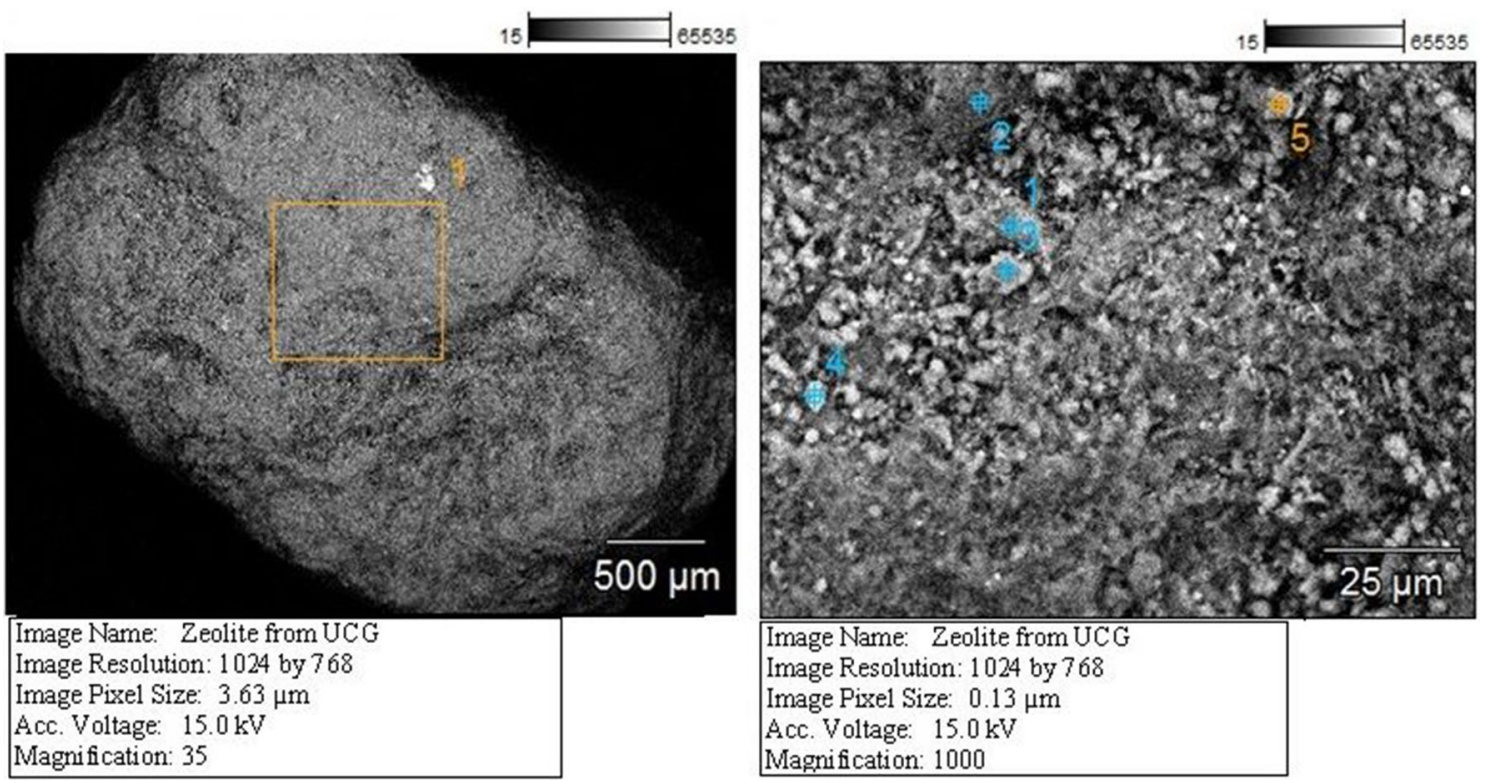

Fig. 10 SEM image of the zeolite sample after gas sorption in a micro-area of 35 and $1000 \times$ magnification
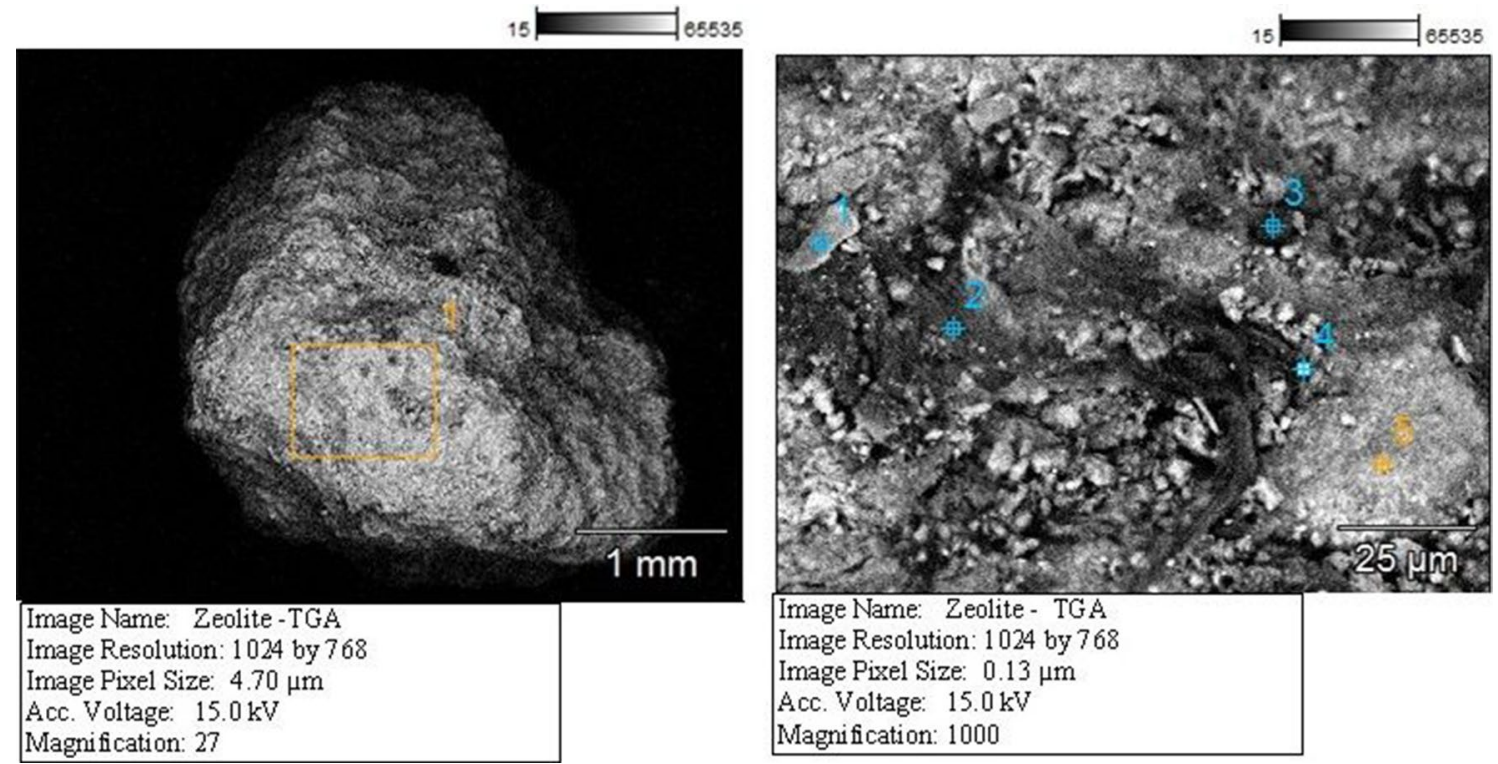

Fig. 11 SEM image of the zeolite sample after gas desorption in a micro-area of 27 and $1000 \times$ magnification

and sulphur were determined on the surface of the samples after sorption and gas desorption.

The surface of zeolite grains consists mainly of silicon, aluminium, potassium, iron, calcium and magnesium. The content of calcium compounds in the zeolite sample after gas sorption and desorption is lower than in the sample before gas sorption. Sulphur compounds in the sample grains after process gas sorption were not determined.

\section{Conclusions}

During the underground coal gasification process, the used reactive material may change its properties. In the event of failure, the material may change in contact with the hot gas or liquid, and the pore size in the material may change. Therefore, it is important to choose the right 
Fig. 12 EDS spectrum of the activated carbon sample before gas sorption in the selected micro-area

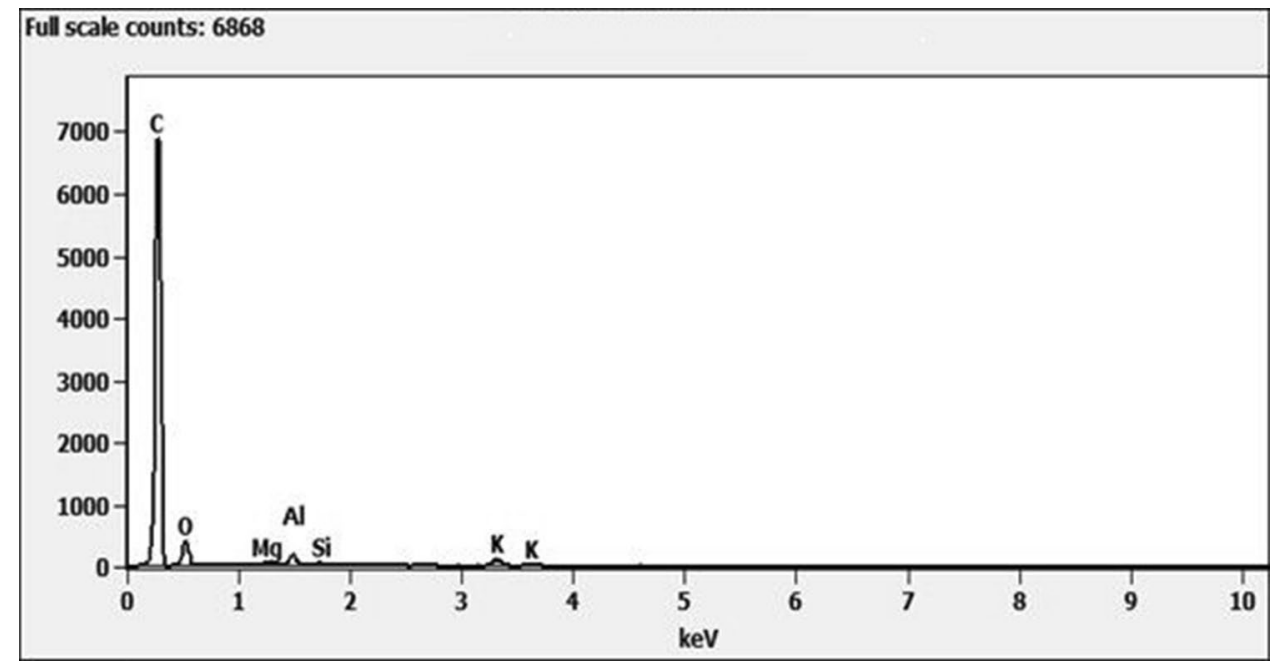

Fig. 13 EDS spectrum of the activated carbon sample after gas sorption in the selected micro-area
Fig. 14 EDS spectrum of the activated carbon sample after gas desorption in the selected micro-area
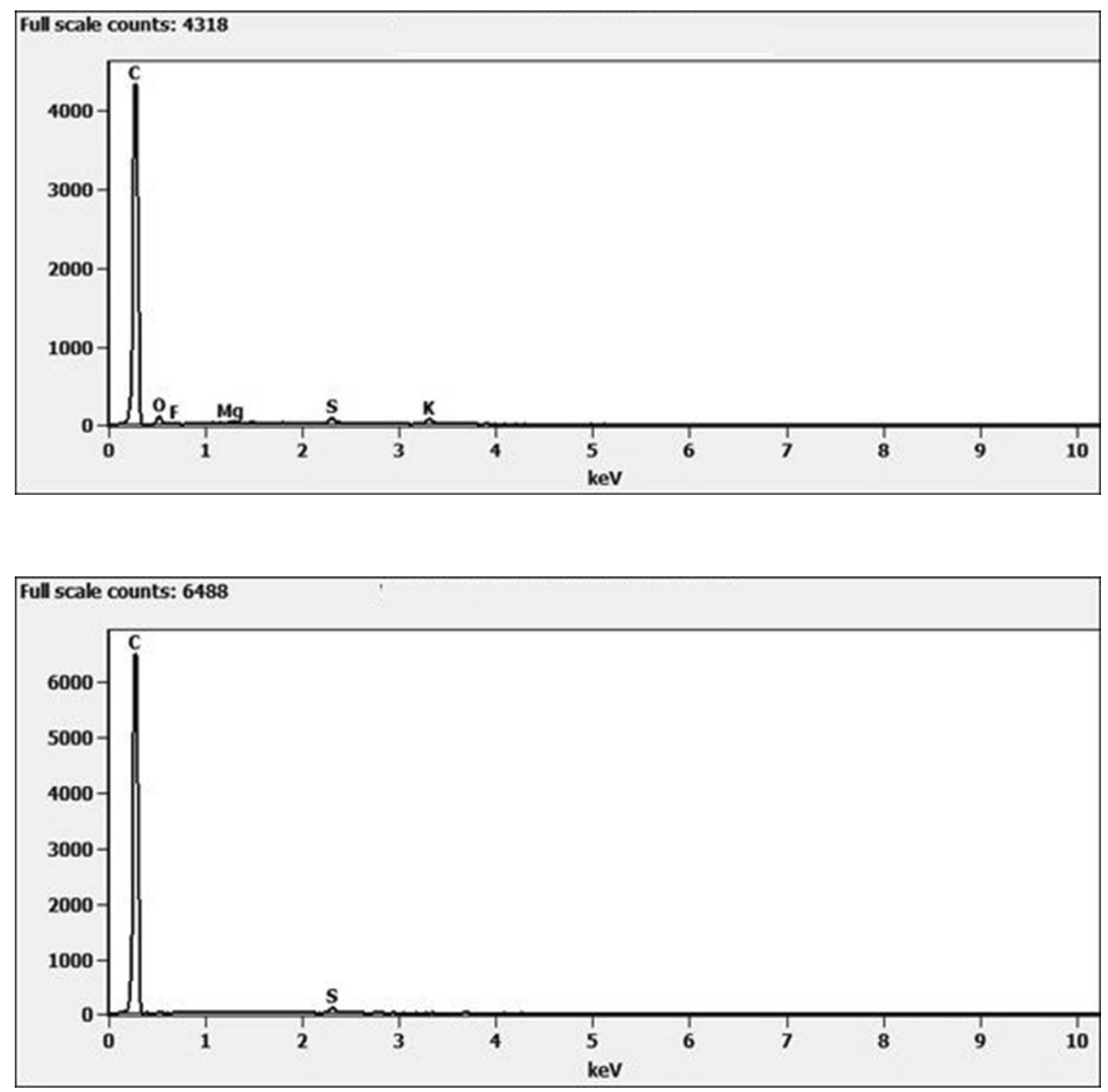

material/materials, which can be used simultaneously for the pollutants generated in the process.

Among the mentioned materials, the carbon sorbents play an important role, characterized by a very extensive and diverse pore system and high selectivity in relation to the sorbed substance. There are wide possibilities to modify the porous system, and easy and cheap methods of regeneration. In addition, among the zeolites, an important feature is the presence of molecules of so-called zeolite water in their composition, which are removed from its structure 
Fig. 15 EDS spectrum of the zeolite sample before gas desorption in the selected micro-area

Fig. 16 EDS spectrum of the zeolite sample after gas sorption in the selected micro-area

Fig. 17 EDS spectrum of the zeolite sample after gas desorption in the selected micro-area

Table 3 Compound of individual elements in the pointtested micro-areas for activated carbon and zeolite
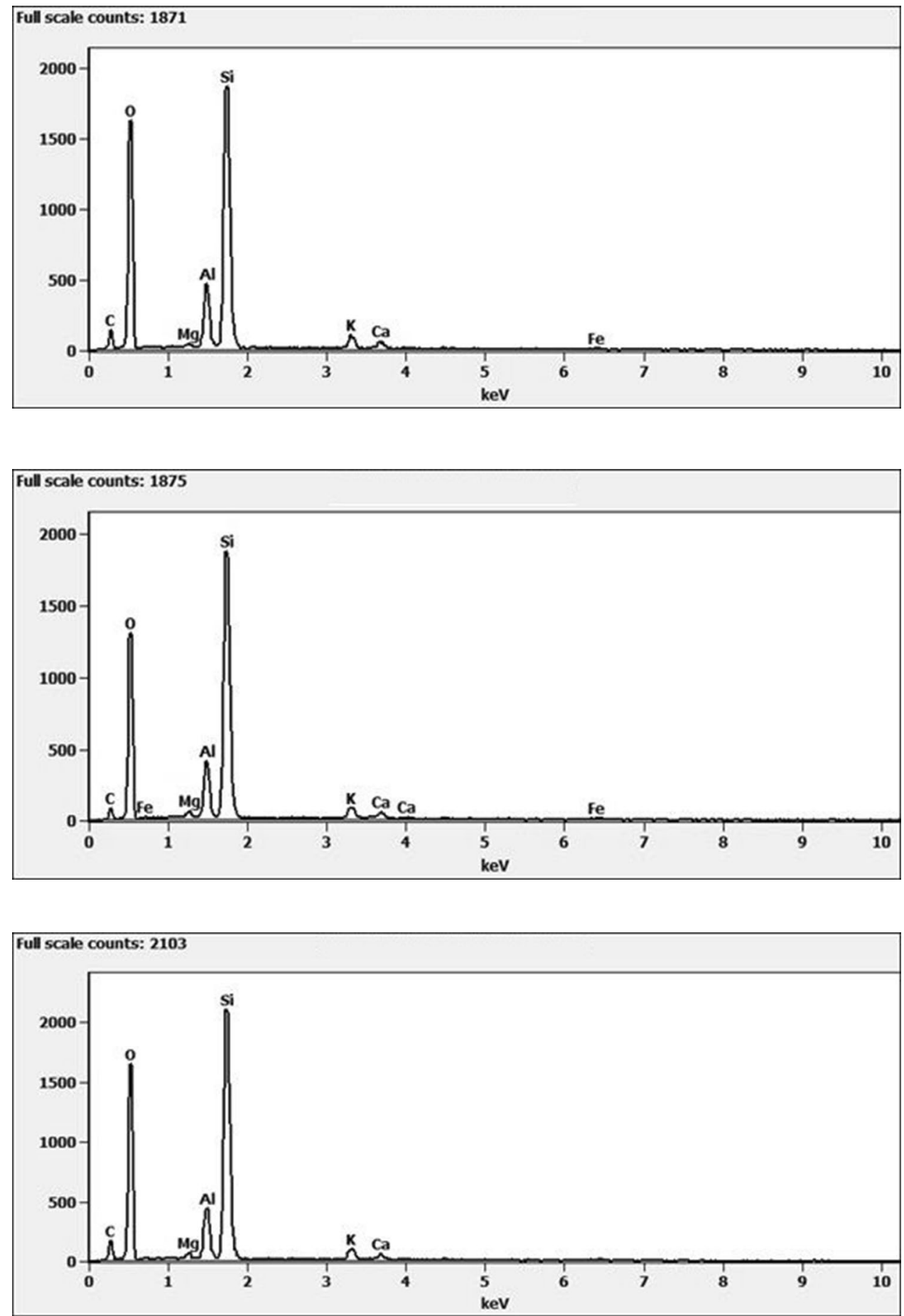

\begin{tabular}{lllllllll}
\hline Sample compound weight \% (av.) & $\mathrm{CO}_{2}$ & $\mathrm{MgO}$ & $\mathrm{Al}_{2} \mathrm{O}_{3}$ & $\mathrm{SiO}_{2}$ & $\mathrm{~K}_{2} \mathrm{O}$ & $\mathrm{CaO}$ & $\mathrm{Fe}_{2} \mathrm{O}_{3}$ & $\mathrm{SO}_{3}$ \\
\hline Activated carbon before gas sorption & 95.15 & 0.49 & 0.34 & 0.24 & 3.77 & - & - & - \\
Activated carbon after gas sorption & 91.01 & 4.19 & - & 0.28 & 0.76 & 0.93 & - & 1.11 \\
Activated carbon after gas desorption & 98.40 & 0.07 & - & 0.06 & - & 0.07 & - & 1.39 \\
Zeolite before gas sorption & 28.66 & 0.52 & 8.30 & 54.04 & 2.70 & 2.13 & 0.85 & 0.23 \\
Zeolite after gas sorption & 13.72 & 0.63 & 10.53 & 66.44 & 3.25 & 3.50 & 1.93 & - \\
Zeolite after gas desorption & 37.42 & 2.70 & 5.97 & 40.80 & 1.99 & 1.05 & 7.39 & 0.13 \\
\hline
\end{tabular}


during heating, leaving the open skeleton crystal structure unchanged. Such structure of minerals provides unique molecular-sieve, sorption and ion-exchange properties, which can be used in the underground reactive barriers.

In this paper, it was confirmed that with the increase of porosity and pore volume, the sorption capacity of the reactive materials increases. In the case of gas sorption, their amount depends additionally on the specifics of a given gas. Carbon dioxide is the gas sorbed in the largest quantities, and the sorption of carbon monoxide and hydrogen occurs in smaller amounts. The percentage of the desorbed gas increases with increasing temperature and depends on the properties of the reactive materials and their sorption capacity.

The material discussed in the article can selectively sorb liquid and gaseous impurities, which can penetrate from the georeactor zone during the process and after its completion. There is currently a need to define mechanisms affecting performance of the reactive materials, which can be used in the UCG process. The main issue concerns effectiveness and time of using of the reactive material. Occasionally, the protective capacity of the deposit can be exceeded, and the gaseous impurities already absorbed by the reactive material can be re-released into the environment. It is necessary to assess the time and quality of the gas flowing through the deposit to determine the optimal size and geometry of the reaction zone, aimed at estimating time of depletion of the sorption capacity of the barrier. Therefore, during the operation, it is necessary to monitor systematically the gas composition leaving the deposit. Long-term research in situ will allow the development of a method for reducing the risk of spread of the pollutants generated during the process to the rock mass. The tests conducted in a large installation would allow the determination of the amount of reactive material or a mixture, and the manner of their use, to improve operational control and safety of conducting the process in the georeactor.

The presented concept can be widely used in geoengineering, especially in the emergency situations related to gas leaks to the environment, underground fires and water pollution with substances of high toxicity. The use of the permeable reactive barrier also aims to reduce migration of the gaseous and liquid pollution from the working environment after exploitation of the deposits.

Acknowledgements The publication was realized within the framework of statutory research GIG no. 11157038-321.

Open Access This article is distributed under the terms of the Creative Commons Attribution 4.0 International License (http://creativeco mmons.org/licenses/by/4.0/), which permits unrestricted use, distribution, and reproduction in any medium, provided you give appropriate credit to the original author(s) and the source, provide a link to the Creative Commons license, and indicate if changes were made.

\section{References}

Dudzińska A (2016) Analiza sorpcji gazów współistniejących w atmosferze kopalnianej. Analysis of sorption of gases present in the mine atmosphere. Przegląd Górniczy T 72(2):10-16

Dudzińska A, Cygankiewicz J (2015) Analysis of adsorption tests of gases emitted in the coal self-heating process. Fuel Process Technol 137:109-116. https://doi.org/10.1016/j.fuproc.2015.04.008

Fadaei S, Moghadam FN, Hashemi M, Pourzamani H (2017) BTEX removal from aqueous solution by modified multi-walled carbon nanotubes with ozone. Anuário do Instituto de Geociências 40(1):235-242. https://doi.org/10.11137/20171235242 (UFRJ ISSN 0101-9759 e-ISSN 1982-3908)

Fronczyk J (2006) Przepuszczalne bariery reaktywne - właściwości materiału aktywnego. Prz. Nauk. Inż. i Kszt. Środ. 33:85-94

Kapusta K, Stańczyk K, Wiatowski M, Chećko J (2013) Environmental aspects of a field-scale underground coal gasification trial in a shallow coal seam at the Experimental Mine Barbara in Poland. Fuel 113:196-208. https://doi.org/10.1016/j.fuel.2013.05.015

Liu S, Li J, Mei M, Dong D (2007) Groundwater pollution from underground coal gasification. Jof China Univ Min Technol 17(4):467472. https://doi.org/10.1016/S1006-1266(07)60127-8

Ludwik-Pardała M (2013) Przegląd przyczyn i mechanizmów migracji gazów powstałych w procesie podziemnego zgazowania węgla. Przegląd Górniczy T. 69(3):77-84 (article-8b95da58-b134-4d05-9f24-be9a136732bf)

Naval Facilities Engineering Command (2012) Permeable reactive barrier cost and performance report, final technical report. TRNAVFAC-ES C-EV-1207. Engineering Service Center, Battelle Memorial Institute N62473-07-D-4013

Obiri-Nyarko F, Malina G, Grajeles J (2014) An overview of permeable reactive barriers for in situ sustainable groundwater remediation. Lit Rev Chemosphere 111:243-259. https://doi.org/10.1016/j. chemosphere.2014.03.112

Połoński M, Pawluk K, Rybka I (2017) Optimization model for the design of multi-layered permeable reactive barriers. Mater Sci Eng 25:245. https://doi.org/10.1088/1757-899x/245/7/072017

Wiatowski M, Kapusta K, Stańczyk K, Stańczyk K (2019) Efficiency assessment of underground gasification of ortho- and metalignite: high-pressure ex situ experimental simulations. Fuel 236:221227. https://doi.org/10.1016/j.fuel.2018.08.143

Wołowiec M, Muir B, Bajda T, Zięba K, Kijak B, Franus W (2017) Removal of BTEX and hexane by organo-zeolites: the influence of surfactant carbon chain length on the sorption process. 19443994/1944-3986. Desalin Water Treat 94:120-128. https://doi. org/10.5004/dwt.2017.21537

Yin S, Herath G, Heng S, Kalpage S (2017) Using permeable reactive barriers to remediate heavy metal-contaminated groundwater through a laboratory column experiment. Original research paper. Am J Environ Sci 13(2):103-115. https://doi.org/10.3844/ajess p.2017.103.115

Zhang W, Ding W, Yiun W (2013) Biological activated carbon treatment for removing BTEX from groundwater. Artic J Environ Eng 139(10):1246-1254. https://doi.org/10.1061/(ASCE)EE.19437870.0000731

Publisher's Note Springer Nature remains neutral with regard to jurisdictional claims in published maps and institutional affiliations. 